\title{
Analysis of the Impact of Magnetic Materials on Cogging Torque in Brushless DC Motor
}

\author{
K. Karthick $\mathbb{D}^{1},{ }^{1}$ S. Ravivarman $\mathbb{D}^{2},{ }^{2}$ Ravi Samikannu, ${ }^{3}$ K. Vinoth $\mathbb{D}^{4},{ }^{4}$ \\ and Bashyam Sasikumar $\mathbb{D}^{5}$ \\ ${ }^{1}$ Department of Electrical and Electronics Engineering, GMR Institute of Technology, Rajam, Andhra Pradesh, India \\ ${ }^{2}$ Department of Electrical and Electronics Engineering, Vardhaman College of Engineering, Shamshabad, Hyderabad, \\ Telangana, India \\ ${ }^{3}$ Department of Electrical Computer and Telecommunications Engineering, Faculty of Engineering and Technology, \\ Botswana International University of Science and Technology, Palapye, Botswana \\ ${ }^{4}$ Department of Electrical and Electronics Engineering, \\ Vel Tech Rangarajan Dr. Sagunthala R\&D Institute of Science and Technology, Chennai, Tamil Nadu, India \\ ${ }^{5}$ Faculty of Mechanical and Production Engineering, Arba Minch University, Arba Minch, Ethiopia \\ Correspondence should be addressed to Bashyam Sasikumar; bashyam.sasikumar@amu.edu.et
}

Received 9 November 2021; Revised 25 November 2021; Accepted 30 November 2021; Published 17 December 2021

Academic Editor: V. Vijayan

Copyright $\odot 2021 \mathrm{~K}$. Karthick et al. This is an open access article distributed under the Creative Commons Attribution License, which permits unrestricted use, distribution, and reproduction in any medium, provided the original work is properly cited.

\begin{abstract}
The cogging torque is the most significant issue in permanent magnet applications, since it has a negative impact on machine performance. In this article, the impact of magnetic materials on cogging torque is analyzed on brushless DC motors (BLDC). The effect of neodymium magnets $(\mathrm{NdFeB})$, compression molded magnet, and samarium cobalt $(\mathrm{SmCo})$ magnet on the cogging torque is analyzed to the BLDC motor designed for hybrid electric vehicle traction that has the peak power rating of $50 \mathrm{~kW}$ motor with 48 stator slots and 8 rotor poles. With the presence of these three magnetic materials, the cogging torque is estimated independently using multiposition simulation. The multiposition is simulated using a transient application that runs at constant speed. The results of cogging torque, rotational speed, angular position of BLDC motor, and magnetic flux density distribution have been presented. Also, the maximal, mean, minimal, rectified mean, and rms values of cogging torque were provided.
\end{abstract}

\section{Introduction}

The BLDC motor is broadly employed in a variety of applications such as home appliances, automotive, aviation, health industry, industrial automation equipment, and instrumentation $[1,2]$. When compared to brushed DC or induction motors, BLDC motors have many advantages, including greater efficiency and consistency, reduced acoustic noise, lighter and smaller size, better dynamic response, improved mechanical characteristics, a broader range of angular velocity, and a long lifespan [3]. Electronic commutation is required for BLDC motors, which helps to reduce the frequency of maintenance [4].

An important category of these motors is the interior permanent magnet brushless DC (IPMBLDC) electrical motor, which is built with magnets embedded into the steel rotor core instead of glued-like surface mounted permanent magnet motors [5-7]. In permanent magnet brushless DC (PMBLDC) motors, cogging torque is a serious issue. Because of the harmonic magnetic forces produced by cogging torque, redundant vibrations and forbidding noises occur in medium-low power PMBLDC motors [8]. As a result, cogging torque reduction methods are essential in PMBLDC motor design. Cogging torque is generated by motors that use permanent magnets, such as PMBLDC motors and permanent magnet synchronous motors (PMSM) [9]. In PMBLDC motor, the rotor is made of permanent magnetic materials and can have any number of pole pairs from two to eight that alternate between north and south. Magnetic interaction between a permanent magnet and steel in a slotted armature is the main reason of cogging torque creation in BLDC motors [10-12]. In this article, we 
analyzed the impact of magnetic materials [13] on cogging torque generation in IPMBLDC motor. Temperature influences magnetism by strengthening or weakening the magnetomotive force. Because the molecules in the magnet accelerate faster when it is heated, the magnetic field weakens.

\section{Related Works}

Various investigations on the cogging torque of PMBLDC motors have been performed over the last two decades. Electromagnetic and mechanical methods have been among those employed [13-16]. Conventional electromagnetic techniques have the drawback of diminishing active magnetic flux, which reduces power output and efficiency. Mechanical methods, on the other hand, minimize active magnetic flux much less than electromagnetic techniques, allowing the construction of high-efficiency, high-power motors. A variety of BLDC motor design factors influence cogging torque such as length of air gap, slot opening, and pole pitch of magnet [17]. These methods to minimize the cogging torque magnitude involve adjusting slot and tooth widths, employing permanent magnet skewing, making auxiliary teeth, using slot-less armatures, and including notches in rotor structure [18-21].

A slot-less core $[19,22]$ has a reduced inductance and can thus operate at quite high speeds. The absence of teeth in the lamination stack minimizes the cogging torque that makes it suitable for low-speed operations as well. The major drawback of a slot-less core is that it is more expensive because more winding is required to compensate the larger air gap [23]. The better torque can be achieved with increase in number of poles. The maximum torque also depends on the strength of the flux density of the material used in the fabrication of permanent magnets. The step size and torque ripples in reluctance machine are influenced by rotor magnetic poles. Presence of large number of poles results in smaller step size as well as lower torque ripple [24-26]. Various analytical methods have been proposed to minimize the cogging torque $[27,28]$. The skewing in rotor structure is one of the major approaches to minimize the cogging torque [29-32]. Because of the permanent magnet construction, the rotor has a high flux density and there are no losses in rotor because of the absence of winding in rotor core. So, the efficiency of the motor is high.

Ferrite magnets have traditionally been used to produce permanent magnets. Rare earth alloy magnets (also known as neodymium magnets) are becoming increasingly popular as technology develops. Ferrite magnets are cost-effective, but they have a less flux density per unit volume. In this article, the slot shape has been fixed as round with slot opening angle of $45^{\circ}$. The impact of magnetic materials on this round stator slot is analyzed for the various magnetic materials.

\section{Design of BLDC Motor}

The configuration or designing of an IPMBLDC motor is more complicated than that of a surface permanent magnet motor. The design process is adopted from [33, 34], as shown in Figure 1. The motor is designed for hybrid electric vehicle traction application with the ratings of peak torque $400 \mathrm{Nm}$, peak speed $6000 \mathrm{rpm}$. Maximum power rating is $50 \mathrm{~kW}$ at $1 / 4$ of maximum speed. The motor has 48 stator slots, 8 rotor poles, outer diameter as $242 \mathrm{Nm}$, and stack length as $75 \mathrm{~mm}$ with an air gap of $0.5 \mathrm{~mm}$. The various BLDC motor parameters are shown in Figure 2. The magnetic pole arc of the rotor is $140^{\circ}$. The slot depth is $30 \mathrm{~mm}$, tooth width is $6.5 \mathrm{~mm}$, and magnetic width per pole is $54 \mathrm{~mm}$. It is observed that the number of excellent quality elements is $97.67 \%$ from the simulation. Lap per pole winding is assumed as 6 and number of coils is assumed as 2 while designing BLDC motor.

The flux in the core is expressed as

$$
\varnothing_{\text {core }} \approx \frac{D}{P} l_{e} B_{g} \text {, }
$$

where $l_{e}$ is the effective length of stator, $B_{g}$ is the flux density in the air gap, $D$ is the stator bore diameter, and $P$ is the number of poles.

The maximum value of the net magnetic flux density $B_{g, p k}$ is defined as

$$
B_{g, \mathrm{pk}}=\frac{B_{r, \mathrm{pk}} * \operatorname{Cos}((\delta-\theta) * \pi / 180)}{\mathrm{PF}} .
$$

The peak winding magnetic flux density $B_{g, p k}$ is expressed as

$$
B_{a, \mathrm{pk}}=B_{g, \mathrm{pk}}(\operatorname{Sin} \theta * \pi / 180)+B_{r, \mathrm{pk}} * \operatorname{Sin}((\delta-\theta) * \pi / 180) \text {, }
$$

where $\mathrm{PF}$ is the power factor, $B_{g, \mathrm{pk}}$ is the peak air-gap magnetic flux density, $\theta$ is the power angle, and $\delta$ is the torque angle.

The pole arc coefficient is expressed as

$$
\alpha_{p} \approx \frac{b}{\tau_{p}}
$$

where $b$ is the arc length of pole shoe and $\tau_{p}$ is the pole pitch.

The cogging torque $\left(T_{\operatorname{cog}}\right)$ is given by

$$
T_{\operatorname{cog}}=\sum_{k=1}^{n} T_{k} \sin \left(k Z \theta_{n}+\alpha_{k}\right),
$$

where $T_{k}$ and $\alpha_{k}$ are the Fourier harmonic development coefficients, $Z$ is the total number of stator teeth, $\theta_{\mathrm{n}}$ is the angular position of the rotor, and $n$ is the harmonics number that defines the actual shape of the cogging torque.

\section{Cogging Torque Analysis}

A multiposition simulation is used to calculate the motor's cogging torque. The speed is chosen as $1 / 6 \mathrm{rpm}$ that corresponds to 1 mechanical degree per second. The angle of the rotor is varied over 1 slot pitch, i.e., 7.5. The analysis is carried out with the range of $0^{\circ}$ to $7.5^{\circ}$ with the step of $0.1875^{\circ}$.

To analyze the effect of three magnetic materials such as $\mathrm{NdFeB}$, compression molded magnet, and SmCo, initially 


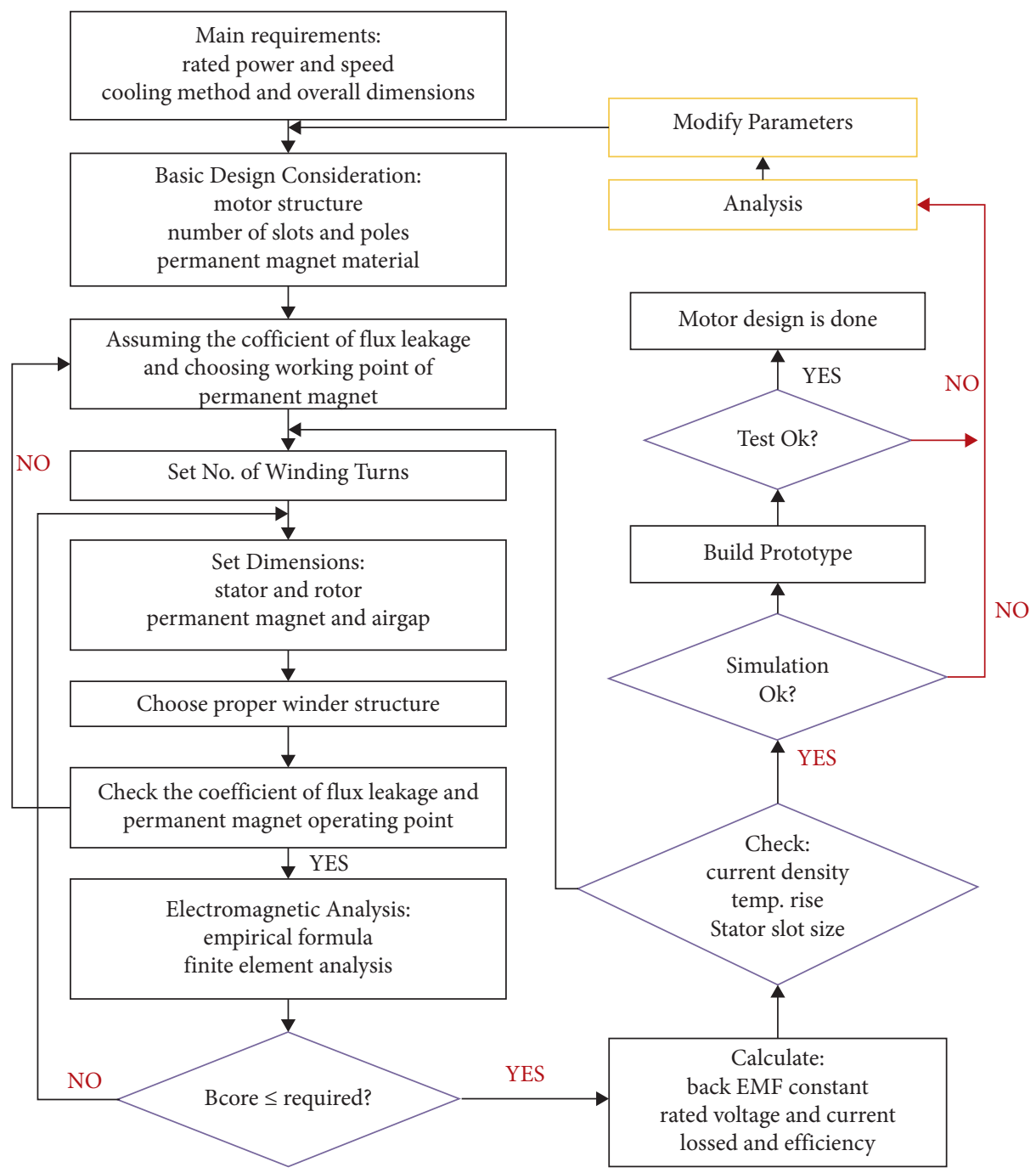

FIGURE 1: BLDC motor designing process [33].

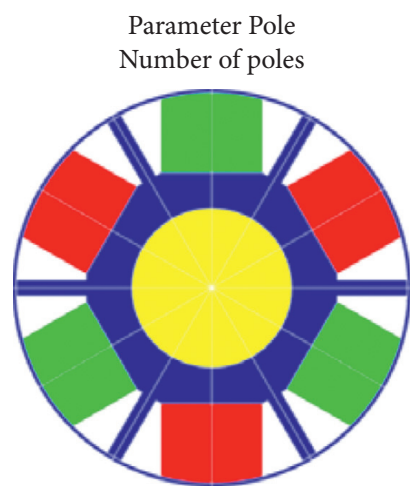

(a)

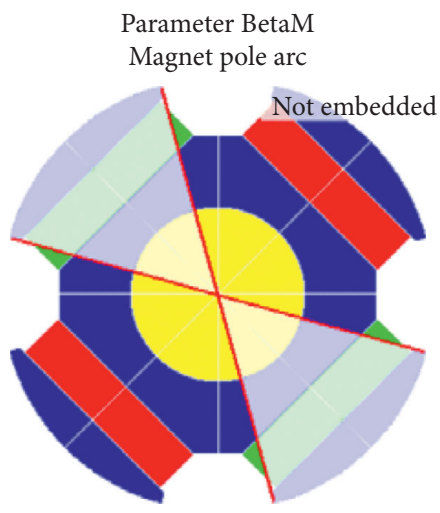

(b)

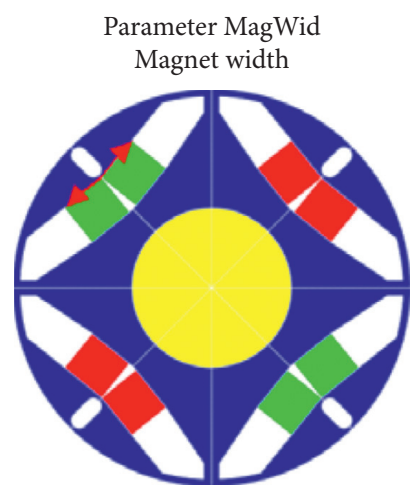

(c)

Figure 2: Continued. 


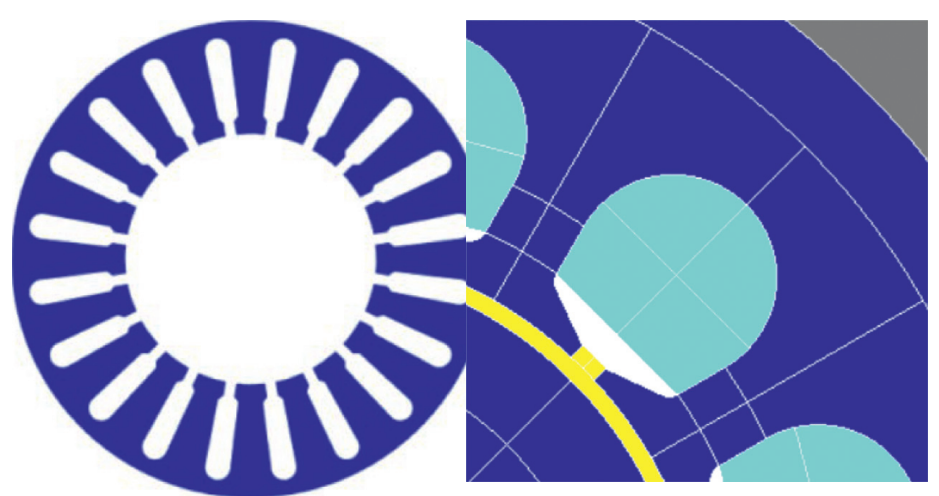

(d)

(e)

Figure 2: BLDC motor parameters. (a) Rotor poles. (b) Magnetic pole arc. (c) Magnetic width. (d) Stator slots. (e) Slot depth and slot opening angle.

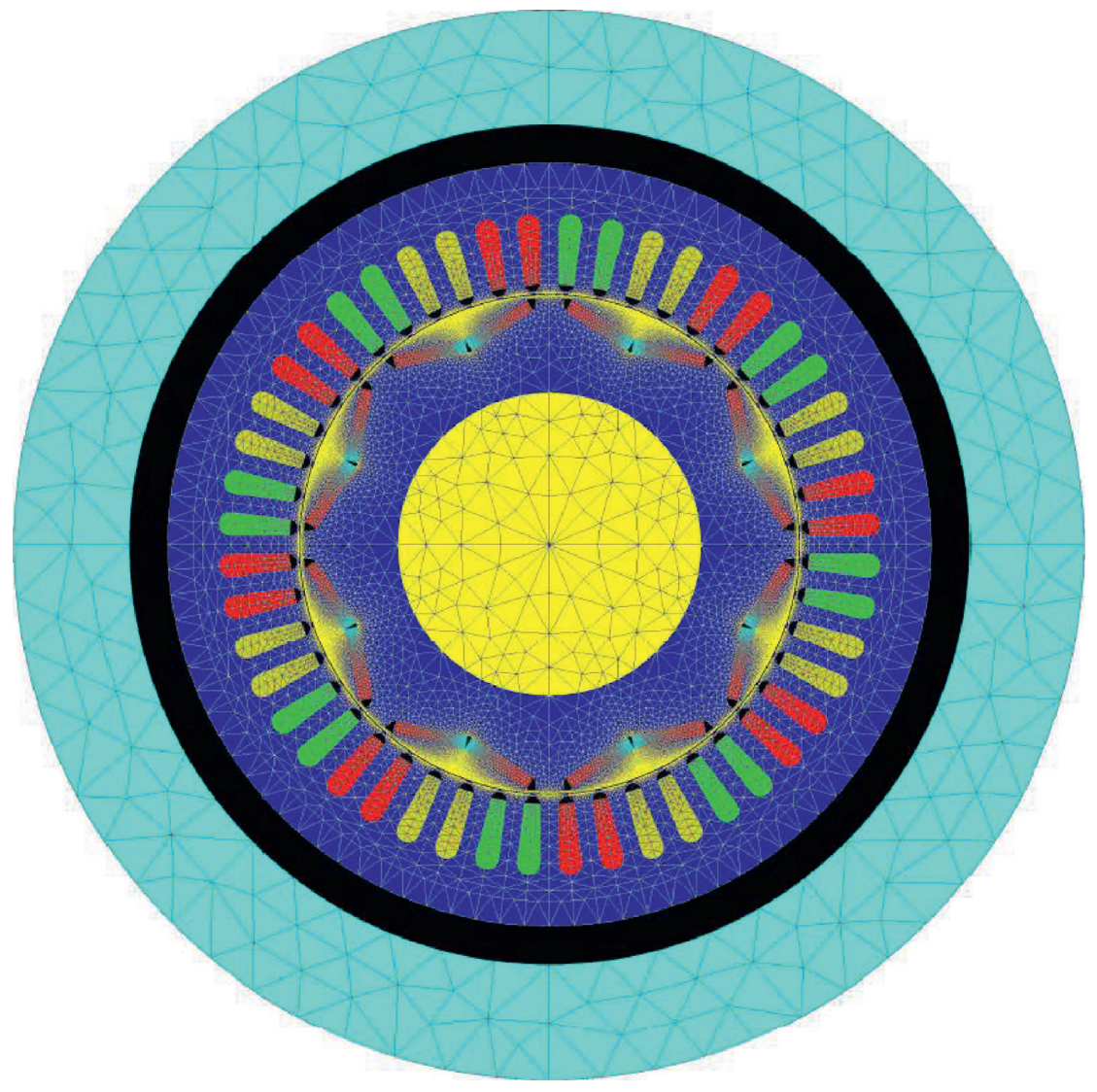

Figure 3: Mesh domain.

TABle 1: Permanent magnet properties.

\begin{tabular}{lccc}
\hline Rotor magnet type & Chemical composition & Remanent flux density (T) & Relative permeability \\
\hline CY_N35_20DEG & NdFeB & 1.21 & 1.052 \\
MQP_B_875_830_150D & NdFeB (compression molded magnet) & 0.545 & 1.3514 \\
NewlandMagnet_Sm2Co17_28F & SmCo & 1.08 & 1.1018 \\
\hline
\end{tabular}

TABLE 2: Magnitude values of BLDC motor parameters.

\begin{tabular}{lccc}
\hline Description & Cogging torque & Angular speed & Angular position \\
\hline Minimal value & -8.044 & 1 & 0 \\
Maximal value & 8.015 & 1 & 7.5 \\
Mean value & -0.022 & 1 & 3.75 \\
Rectified mean value & 3.798 & 1 & 3.75 \\
R.M.S value & 4.689 & 1 & 4.33 \\
\hline
\end{tabular}


TABLE 3: Magnitude values of BLDC motor parameters for Case 1.

\begin{tabular}{lccc}
\hline Description & Cogging torque & Angular speed & Angular position \\
\hline Minimal value & -0.793 & 1 & 0 \\
Maximal value & 0.784 & 1 & 7.5 \\
Mean value & -0.003 & 1 & 3.75 \\
Rectified mean value & 0.274 & 1 & 3.75 \\
R.M.S value & 0.395 & 1 & 4.33 \\
\hline
\end{tabular}

TABLe 4: Magnitude values of BLDC motor parameters for Case 3.

\begin{tabular}{lccc}
\hline Description & Cogging torque & Angular speed & Angular position \\
\hline Minimal value & -4.589 & 1 & 0 \\
Maximal value & 4.566 & 1 & 7.5 \\
Mean value & -0.017 & 1 & 3.75 \\
Rectified mean value & 1.913 & 1 & 3.75 \\
R.M.S value & 2.486 & 1 & 4.33 \\
\hline
\end{tabular}

EVOLUTIVECURVE2D_1

Mechanical set/Magnetic torgue [ROTOR]

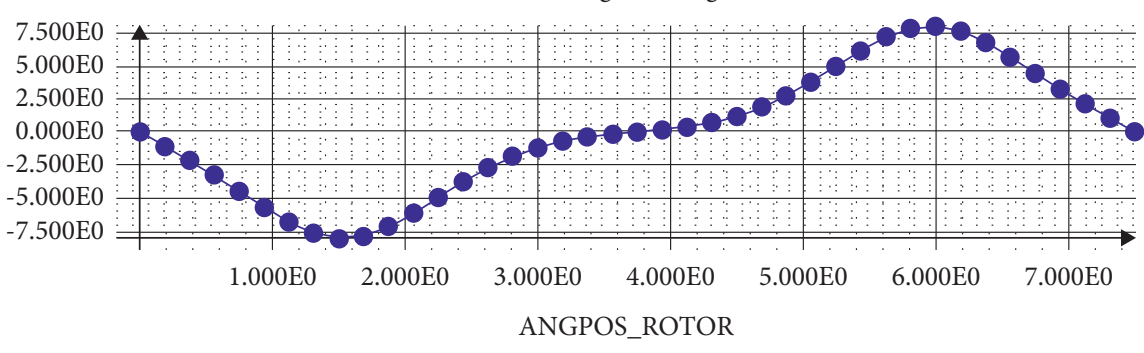

- Mechanical set/Magnetic torque [ROTOR] (N.m)

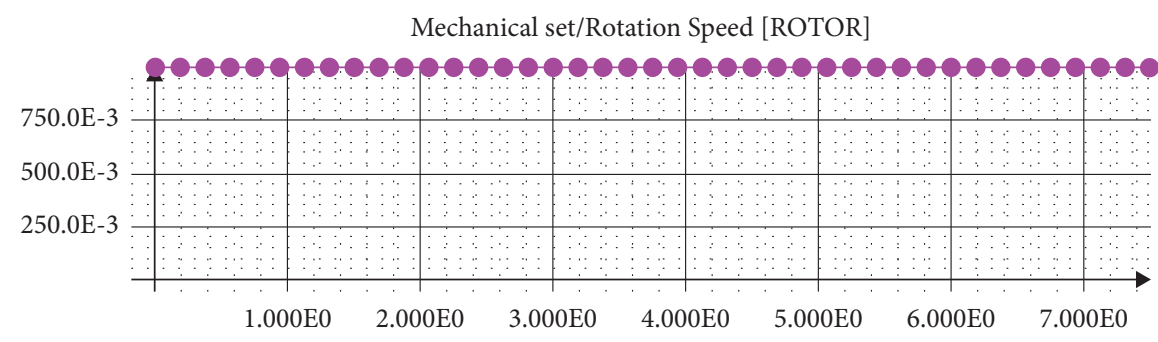

ANGPOS_ROTOR

- Mechanical set/Rotation Speed [ROTOR] (deg/s)

Mechanical set/Position [ROTOR]

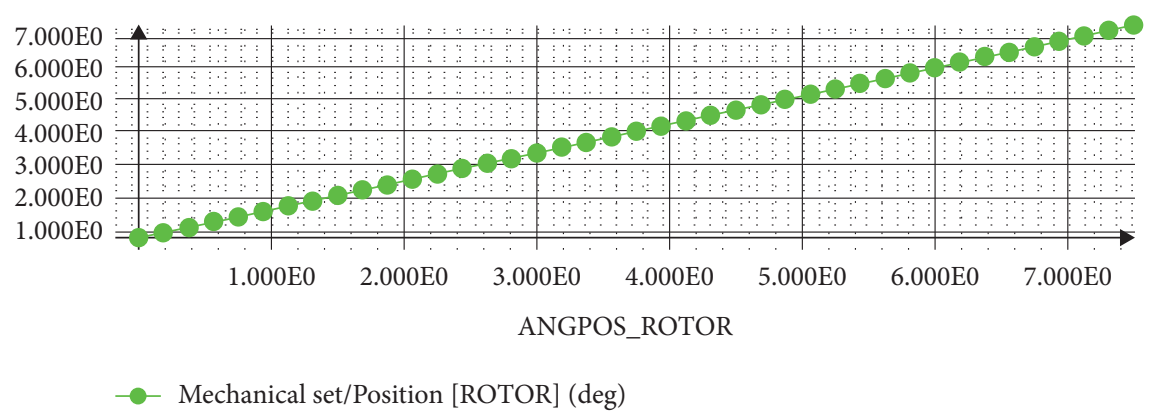

FIGURE 4: Cogging torque, rotational speed, and angular position of BLDC motor for Case 1. 

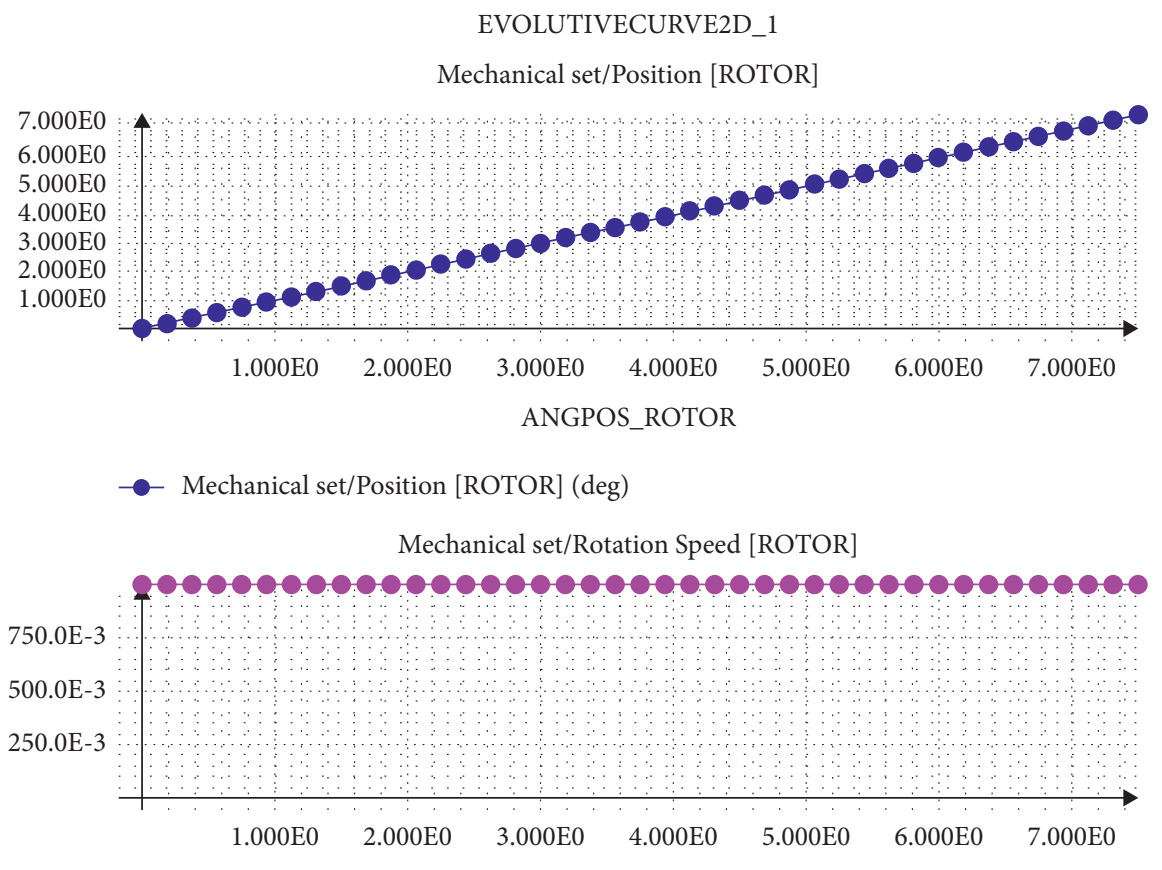

ANGPOS_ROTOR

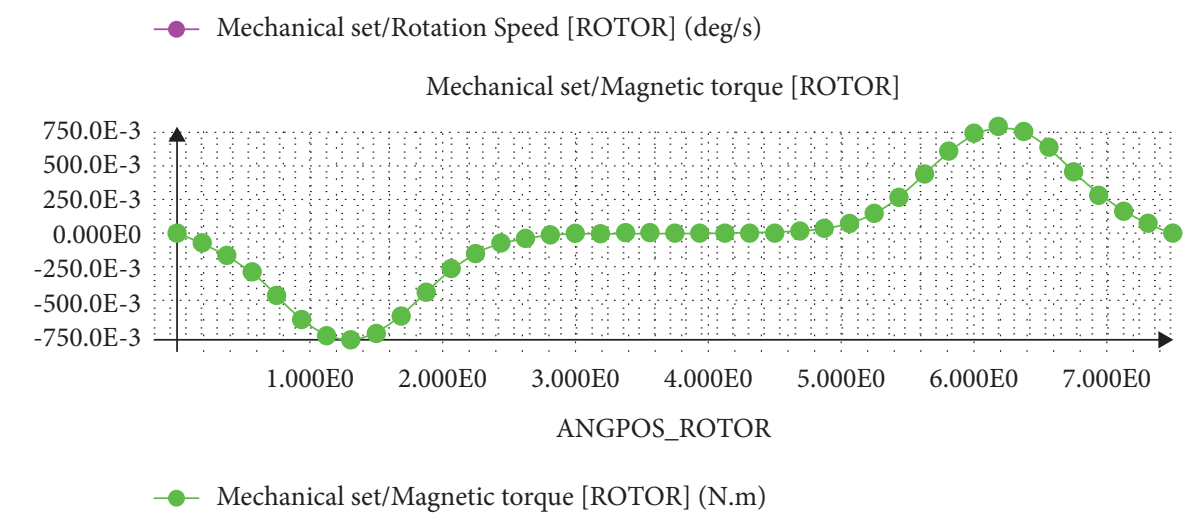

FIgure 5: Angular position, rotational speed, and cogging torque of BLDC motor for Case 2.

the mesh generation has been done, as shown in Figure 3, by defining the geometric parameters. The COGENT_M270_35A_50HZ is the silicon steel lamination that has been chosen as the core.

Table 1 shows the properties of $\mathrm{NdFeB}$, compression molded magnet, and SmCo. It is observed that compression molded magnet has very low remanent flux density with high relative permeability. The main components of a compression molded magnet are isotropic $\mathrm{NdFeB}$ powder and a thermosetting binder. They have improved mechanical properties [35].

4.1. Results and Discussion. The three magnetic material impacts have been given as Case 1, 2, and 3 for $\mathrm{NdFeB}$, compression molded magnet, and SmCo magnetic materials, respectively. Tables $2-4$ give the numerical results of cogging torque, angular speed, and angular position for
$\mathrm{NdFeB}$, compression molded magnet, and SmCo magnetic materials, respectively. The graphical results of the same are shown in Figures 4-6, respectively. Magnetic flux density distribution of the machine is shown in Figures 7-9 for the presence of rotor permanent magnets $\mathrm{NdFeB}$, compression molded magnet, and SmCo, respectively. The cogging torque maximum magnitudes are $8.015 \mathrm{Nm}, 0.784 \mathrm{Nm}$, and $4.566 \mathrm{Nm}$ for $\mathrm{NdFeB}$, compression molded magnet, and SmCo, respectively. It is observed that the composite molded magnets help to reduce the impact of cogging torque. All these results have been obtained in constant angular speed.

Case 1. CY_N35_20DEG magnetic material.

Case 2. compression molded magnet.

Case 3. NewlandMagnet_Sm2Co17_28F. 
EVOLUTIVECURVE2D 1 1

Mechanical set/Position [ROTOR]

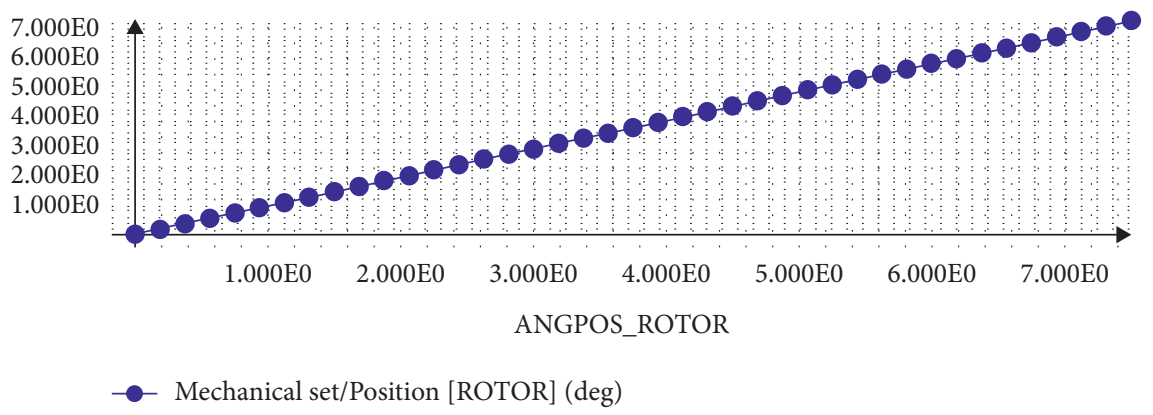

Mechanical set/Rotation Speed [ROTOR]

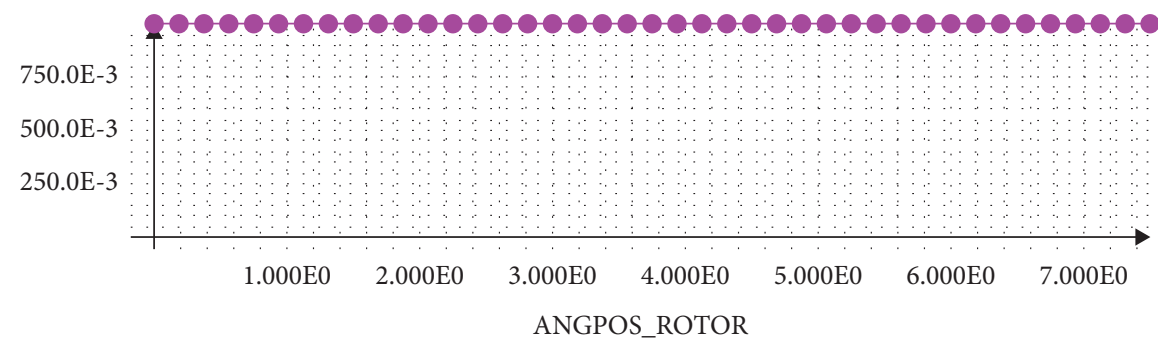

- Mechanical set/Rotation Speed [ROTOR] (deg/s)

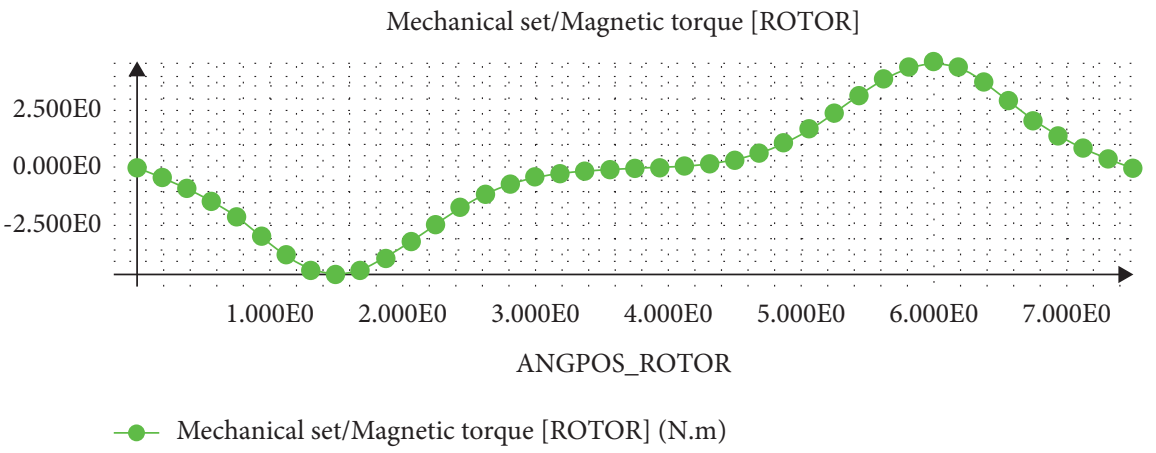

FIGURE 6: Angular position, rotational speed, and cogging torque of BLDC motor for Case 3.
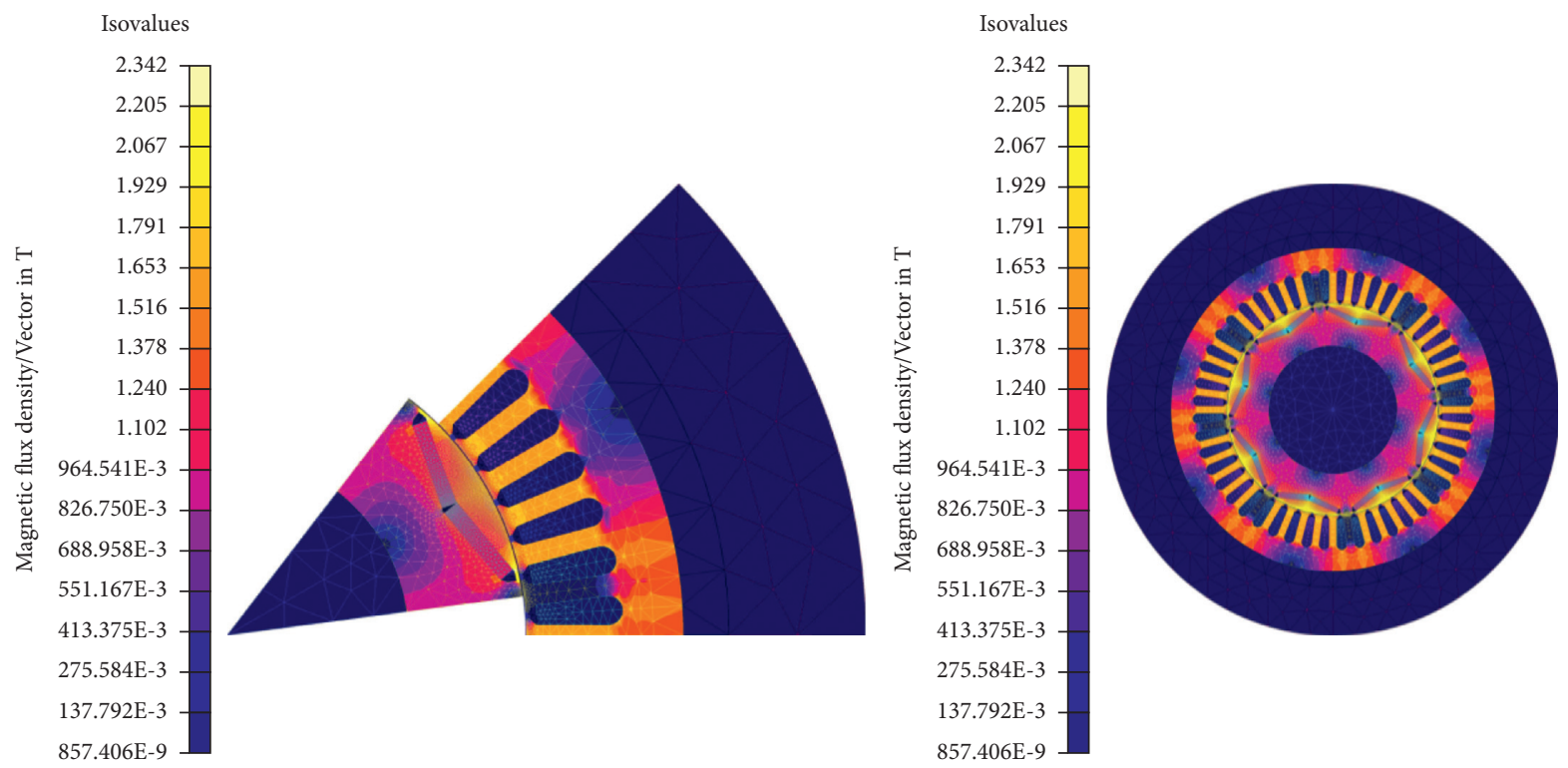

FIgure 7: Magnetic flux density distribution view of BLDC motor of Case 1. 

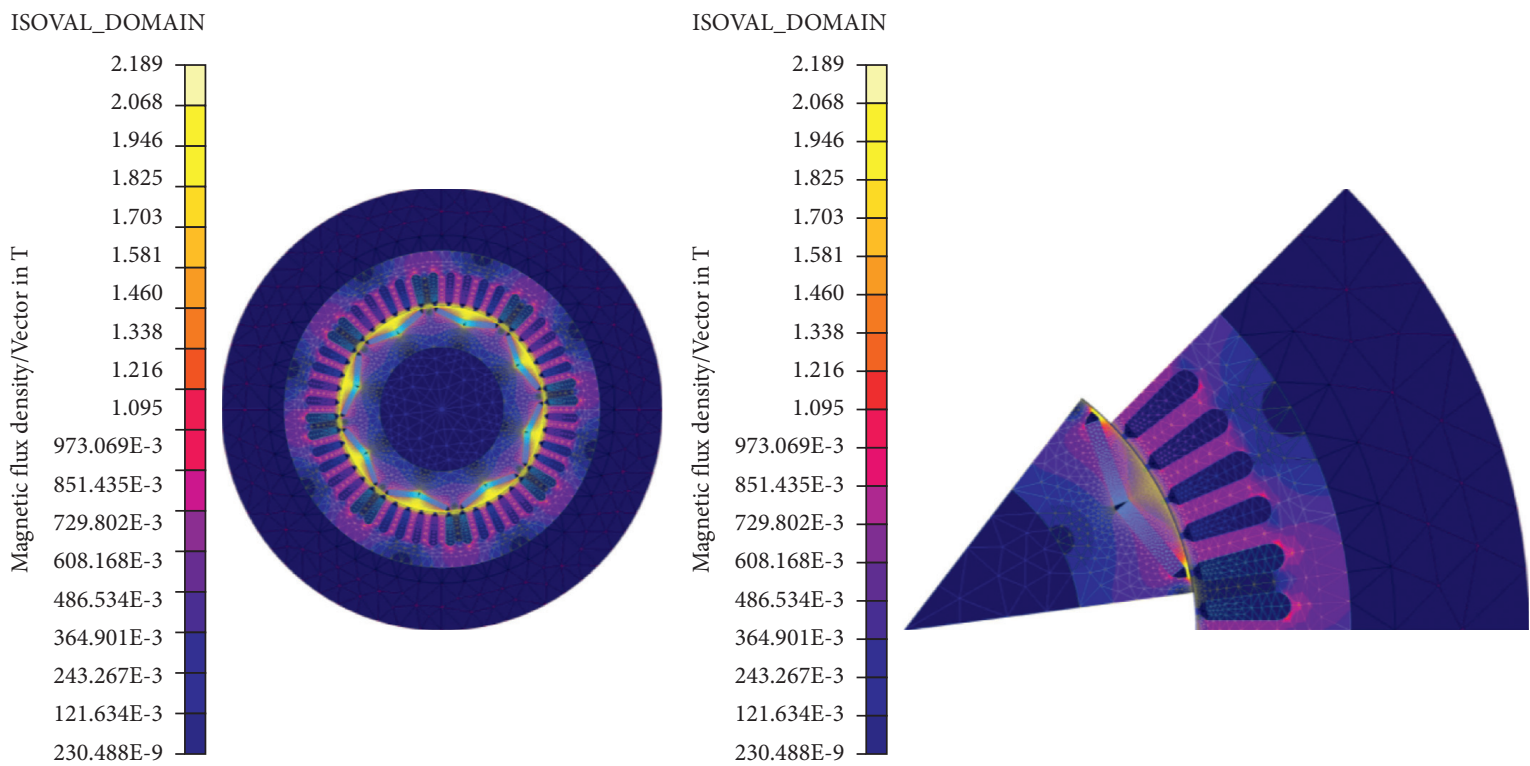

Figure 8: Magnetic flux density distribution view of BLDC motor of Case 2.
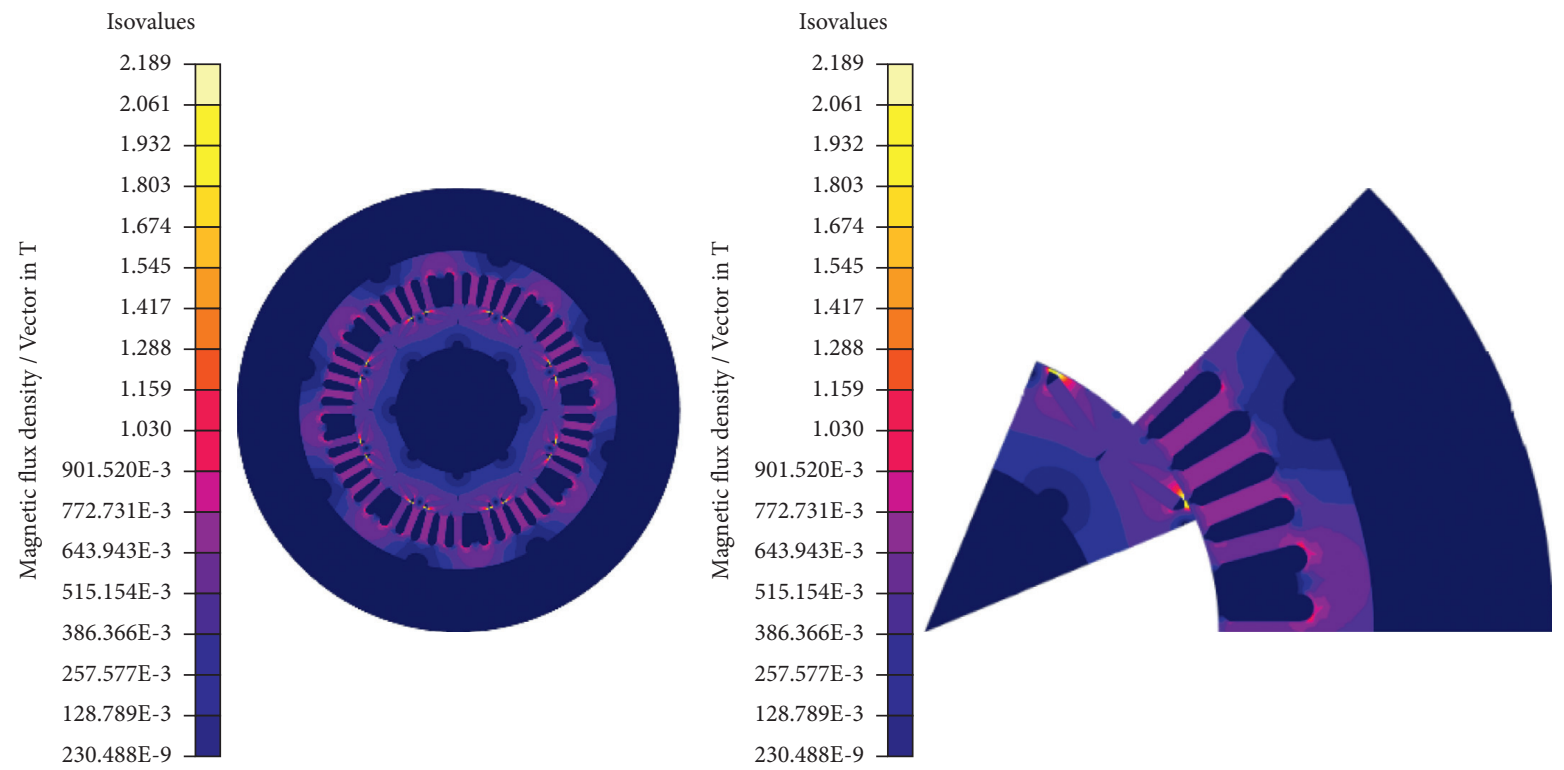

Figure 9: Magnetic flux density distribution view of BLDC motor of Case 3.

\section{Conclusion}

In this paper, the impact of $\mathrm{NdFeB}$, compression molded magnet, and SmCo on cogging torque has been analyzed. The results shows that the cogging torque maximum magnitudes are $8.015 \mathrm{Nm}, 0.784 \mathrm{Nm}$, and $4.566 \mathrm{Nm}$ for $\mathrm{NdFeB}$, compression molded magnet, and SmCo, respectively. SmCo reduces the impact to $56.9 \%$ as compared to $\mathrm{NdFeB}$. The compressed molded magnet has the large reduction in cogging torque magnitude as $97.8 \%$. The results have been obtained by creating mechanical set parameters, mesh generation, and physic description using flux simulation tool. The initial rotor position has been set to $7.5^{\circ}$ to align the phase current with back emf. The selection of magnetic material will primarily depend on the temperature of the application, device size and weight, and cost. According to the existing research, $\mathrm{NdFeB}$ outperforms SmCo in terms of flux output between $-138^{\circ} \mathrm{C}$ and $150^{\circ} \mathrm{C}$. Above $150^{\circ} \mathrm{C}, \mathrm{NdFeB}$ continues to suffer enough induction loss that $\mathrm{SmCo}$ is superior.

\section{Data Availability}

The data used to support the findings of this study are included within the article. 


\section{Conflicts of Interest}

The authors declare that there are no conflicts of interest regarding the publication of this paper.

\section{References}

[1] N. Mousavi, T. Rahimi, and H. Meshgin Kelk, "Reduction EMI of BLDC motor drive based on software analysis," Advances in Materials Science and Engineering, vol. 2016, Article ID 1497360, 9 pages, 2016.

[2] K. Karthick, K. Jaiganesh, and S. Kavaskar, "Comprehensive study, design and economic feasibility analysis of solar PV powered water pumping system," Energy Engineering, vol. 118, no. 6, pp. 1887-1904, 2021.

[3] C. Xiang, X. Wang, Ma Yue, and B. Xu, "Practical modeling and comprehensive system identification of a BLDC motor," Mathematical Problems in Engineering, vol. 2015, Article ID 879581, 11 pages, 2015.

[4] O. Imoru and J. Tsado, "Modelling of an electronically commutated (Brushless DC) motor drives with back-emf sensing," in Proceedings of the 2012 16th IEEE Mediterranean Electrotechnical Conference, pp. 828-831, Yasmine Hammamet, Tunisia, March 2012.

[5] H.-S. Ko and K.-J. Kim, "Characterization of noise and vibration sources in interior permanent-magnet brushless DC motors," IEEE Transactions on Magnetics, vol. 40, no. 6, pp. 3482-3489, 2004, Nov. 2004.

[6] D. Woo-Cheol Lee and W. Lee, "Analysis of relationship between abnormal current and position detection error in sensorless controller for interior permanent-magnet brushless DC motors," IEEE Transactions on Magnetics, vol. 44, no. 8, pp. 2074-2081, 2008.

[7] F. Yaojing, Y. Kai, H. Shoudao, G. Lei, and Z. Wenjuan, "Research of interior permanent magnet brushless DC motor for electric vehicles," in Proceedings of the 2013 International Conference on Electrical Machines and Systems (ICEMS), pp. 1074-1079, Busan, October 2013.

[8] T. A. Anuja and M. A. N. Doss, "Reduction of cogging torque in surface mounted permanent magnet brushless DC motor by adapting rotor magnetic displacement," Energies, vol. 14, no. 10, p. 2861, 2021.

[9] V. Uma Sabareesh and K. Karthick, "Solar PV based permanent magnet synchronous motor drive for water pumping application," International Journal of Innovative Technology and Exploring Engineering, vol. 8, no. 9, pp. 837-843, 2019.

[10] Y.-K. Lin, Y.-N. Hu, T.-K. Lin et al., "A method to reduce the cogging torque of spindle motors," Journal of Magnetism and Magnetic Materials, vol. 209, no. 1-3, pp. 180-182, 2000, ISSN 0304-8853.

[11] J. Y. Song, K. J. Kang, C. H. Kang, and G. H. Jang, “Cogging torque and unbalanced magnetic pull due to simultaneous existence of dynamic and static eccentricities and uneven magnetization in permanent magnet motors," IEEE Transactions on Magnetics, vol. 53, no. 3, p. 1, 2016 Art no. 8200609.

[12] V. Zamani Faradonbeh and S. Taghipour Boroujeni, N. Takorabet and N. Takorabet, Optimum arrangement of PMs in surface-mounted PM machines: cogging torque and flux density harmonics," Electrical Engineering, vol. 102, no. 3, pp. 1117-1127, 2020.

[13] W. Herlina, A. Rahardjo, B. Sudiarto, and R. Setiabudy, "The implement of permanent magnet material variations on the reduction of cogging torque in PMSG," IOP Conference Series:
Materials Science and Engineering, vol. 620, Article ID 012101, 2019.

[14] O. Kudrjavtsev and A. Kilk, "Cogging torque reduction methods," in Proceedings of the 2014 Electric Power Quality and Supply Reliability Conference (PQ), pp. 251-254, Rakvere, Estonia, June 2014.

[15] Z. H. A. O. Wei-you, C. H. E. N. Yi-guang, S. H. E. N. Yonghuan, and X. I. N. G. Sheng-zhi, "Effective methods of reducing cogging torque in flux reversal machine," Journal of Iron and Steel Research, International, vol. 13, no. Supplement 1, pp. 444-449, 2006, ISSN 1006-706X.

[16] T. Nur, L. E. Joe, M. Siregar, L. E. Joe, and M. Siregar, "Novel of cogging torque reduction technique for permanent magnet generator by compounding of magnet edge shaping and dummy slotting in stator core," International Journal of Advanced Science, Engineering and Information Technology, vol. 10, no. 3, pp. 1191-1199, 2020.

[17] A. Jagadeeshwaran and S. Padma, "Comparative study of cogging torque for different tooth gap width and airgap flux of PMBLDC motor for motion control applications," International Journal of Electrical Engineering, vol. 5, no. 6, pp. 783-790, 2012.

[18] G. González-Palomino, J. Rivas-Conde, and E. Laniado, "Optimization of permanent magnet skew in permanent magnet linear synchronous motors using finite element and statistical method," Engineering, vol. 03, no. 06, pp. 577-582, 2011.

[19] J.-M. Seo, J.-H. Kim, I.-S. Jung, and H.-K. Jung, "Design and analysis of slotless brushless DC motor," IEEE Transactions on Industry Applications, vol. 47, no. 2, pp. 730-735, 2011, March-April 2011.

[20] H.-Y. Lee, S.-Y. Yoon, S.-O. Kwon, J.-Y. Shin, S.-H. Park, and M.-S. Lim, "A study on a slotless brushless DC motor with toroidal winding," Processes, vol. 9, no. 11, p. 1881, 2021.

[21] H. Ou, Y. Hu, Z. Mao, and Y. Li, "A method for reducing cogging torque of integrated propulsion motor," Journal of Marine Science and Engineering, vol. 7, no. 7, p. 236, 2019.

[22] H. Lee, E. Lee, G. Lee, and S. Kwon, "Evaluation of slotless permanent synchronous motor with toroidal winding," in Proceedings of the 2019 IEEE Energy Conversion Congress and Exposition (ECCE), pp. 1735-1738, Baltimore, MD, USA, September 2019.

[23] V. Préault and C. Espanet, "A topology of low noise polygonal slotless BLDC motor designed for high volume production," in Proceedings of the 2020 23rd International Conference on Electrical Machines and Systems (ICEMS), pp. 34-38, Hamamatsu, Japan, November 2020.

[24] Y. Ji, B. Li, and J. Sun, "Harmonic analysis on torque ripple of brushless DC motor based on advanced commutation control," Journal of Control Science and Engineering, vol. 2018, Article ID 3530127, 9 pages, 2018.

[25] Z. Q. Zhu, S. Ruangsinchaiwanich, N. Schofield, and D. Howe, "Reduction of cogging torque in interior-magnet brushless machines," in Proceedings of the 2003 IEEE International Magnetics Conference (INTERMAG), Boston, MA, USA, April 2003.

[26] S.-M. Sang-Moon Hwang, fnm Jae-Boo Eom, fnm Yoong-Ho Jung, fnm Deug-Woo Lee, and fnm Beom-Soo Kang, "Various design techniques to reduce cogging torque by controlling energy variation in permanent magnet motors," IEEE Transactions on Magnetics, vol. 37, no. 4, pp. 2806-2809, 2001.

[27] Li Li Zhu, S. Z. Jiang, Z. Q. Zhu, and C. C. Chan, "Analytical methods for minimizing cogging torque in permanent- 
magnet machines," IEEE Transactions on Magnetics, vol. 45, no. 4, pp. 2023-2031, 2009.

[28] S. Nian, L. Zhu, X. Luo, and Z. Huang, "Analytical methods for optimal rotor step-skewing to minimize cogging torque in permanent magnet motors," in Proceedings of the 2019 22nd International Conference on Electrical Machines and Systems (ICEMS), pp. 1-5, Harbin, China, August 2019.

[29] M. Aydin and M. Gulec, "Reduction of cogging torque in double-rotor axial-flux permanent-magnet disk motors: a review of cost-effective magnet-skewing techniques with experimental verification," IEEE Transactions on Industrial Electronics, vol. 61, no. 9, pp. 5025-5034, 2014.

[30] L. Jia, M. Lin, W. Le, N. Li, and Y. Kong, "Dual-skew magnet for cogging torque minimization of axial flux PMSM with segmented stator," IEEE Transactions on Magnetics, vol. 56, no. 2, pp. 1-6, 2020.

[31] H. Wang, P. Guan, S. Liu, S. Wu, T. Shi, and L. Guo, "Modeling and analyzing for magnetic field of segmented surface-mounted PM motors with skewed Poles," Journal of Electrical Engineering \& Technology, vol. 1, pp. 1-13, 2021.

[32] I.-H. Jo, H.-W. Lee, G. Jeong, W.-Y. Ji, and C.-B. Park, "A study on the reduction of cogging torque for the skew of a magnetic geared synchronous motor," IEEE Transactions on Magnetics, vol. 55, no. 2, pp. 1-5, 2019.

[33] C. He and T. Wu, "Permanent magnet brushless DC motor and mechanical structure design for the electric impact wrench system," Energies, vol. 11, no. 6, p. 1360, 2018.

[34] J. Chu, I. Moon, G. Choi, J. Ryu, and M. Mun, "Design of BLDC motor controller for electric power wheelchair," in Proceedings of the IEEE International Conference on Mechatronics, 2004. ICM'04, pp. 92-7e, Istanbul, Turkey, June 2004.

[35] K. Mungale, T. N. Lamichhane, H. Wang, B. C. Sales, and M. Parans Paranthaman, "Uday Kumar Vaidya, Compression molding of anisotropic $\mathrm{NdFeB}$ bonded magnets in a polycarbonate matrix," Materialia, vol. 19, Article ID 101167, 2021, ISSN 2589-1529. 